Cell Research (2003); 13(4):301-308

http://www.cell-research.com

\title{
Cloning and molecular characterization of a novel lectin gene from Pinellia
} ternata

\author{
Jian Hong YAO ${ }^{1}$, Xiu Yun ZHAO ${ }^{1}$, Zhi Hua LIAO ${ }^{1}$, Juan LIN ${ }^{1}$, Zhong Hai CHEN ${ }^{1}$, Fei CHEN ${ }^{1}$, Jun SONG ${ }^{1}$, \\ Xiao Fen SUN ${ }^{1}, \mathrm{Ke}_{\mathrm{XuAN}}$ TANG ${ }^{1,2, *}$ \\ 1 State Key Laboratory of Genetic Engineering, School of Life Sciences, Morgan-Tan International Center for Life \\ Sciences, Fudan-SJTU-Nottingham Plant Biotechnology R and D Center, Fudan University, Shanghai 200433, \\ China \\ 2 Fudan-SJTU-Nottingham Plant Biotechnology R and D Center, Plant Biotechnology Research Center, School of \\ Agriculture and Biology, Shanghai Jiaotong University, Shanghai 200030, China
}

\begin{abstract}
The full-length cDNA of Pinellia ternata agglutinin (PTA) was cloned from inflorescences using RACE-PCR. Through comparative analysis of PTA gene (pta) and its deduced amino acid sequence with those of other Araceae species, pta was found to encode a precursor lectin with signal peptide and to have extensive homology with those of other Araceae species. PTA was a heterotetrameric mannose-binding lectin with three mannosebinding boxes like lectins from other Araceae and Amaryllidaceae species. Southern blot analysis of the genomic DNA revealed that pta belonged to a low-copy gene family. Northern blot analysis demonstrated that pta constitutively expressed in various plant tissues including root, leaf, stem and inflorescence. The pta cDNA sequence encoding for mature PTA protein was cloned into pET-32a plasmid and the resulting plasmid, pET32a-PTA containing Trx-PTA fusion protein, was investigated for the expression in E. coli BL21. SDS-PAGE gel analysis showed that the Trx-PTA fusion protein was successfully expressed in E. coli BL21 when induced by IPTG. Artificial diet assay revealed that PTA fusion protein had significant levels of resistance against peach potato aphids when incorporated into artificial diet at $0.1 \%(\mathrm{w} / \mathrm{v})$. The cloning of the pta gene will enable us to further test its effect in depth on aphids by transferring the gene into crop plants.
\end{abstract}

Key words: araceae, cDNA cloning, lectin, Pinellia ternata, RACE-PCR.

\section{INTRODUCTION}

Using pest-resistant varieties to control pests in various crop species is very economic, effective and safe compared with using pesticides. However, conventional breeding of such plants is a difficult and long process, which has not been so successful for insect resistance. A very important group of insects that suck

\footnotetext{
* Correspondence: Prof. Ke Xuan Tang
}

Tel: 0086-21-65642772 Fax: 0086-21-65648376

E-mail: kxtang1@yahoo.com or kxtang1@sohu.com

Received Nov-7-2002 Revised June-18-2003 Accepted June-232003 the phloem of plants (including aphids and planthoppers) was proven difficult to control by conventional plant breeding, a matter made worse by their importance as vectors of plant viruses[1]. Recent studies showed that some plant lectins were toxic to sapsucking insects in artificial diet assays[2, 3], among which the lectin (GNA) from snowdrop (Galanthus nivalis), encoded by the gna gene, was the most toxic. Transgenic tobacco and rice expressing GNA showed significant insecticidal activity towards the peach potato aphids (Myzus persicae Sulzer)[4] and rice planthoppers including Nilaparvata lugens[5, 6] and 
Laodelphax striatellus[7] respectively in bioassay and feeding tests.

Pinellia pedatisecta and Pinellia ternata are traditional Chinese medicinal plant species, belonging to family Araceae. Recent insect bioassay studies showed that lectins from $\mathrm{P}$. pedatisecta and P. ternata had significant insecticidal activities towards cotton aphids (Aphis gossypii Glover) and peach potato aphids (M. persicae Sulzer) when incorporated into artificial diets at $1.2 \mathrm{~g} / \mathrm{L}$ and $1.5 \mathrm{~g} / \mathrm{L}$ respectively[8, 9]. The insecticidal activities of Pinellia lectins are very similar to that of GNA, making Pinellia lectins potential candidates in controlling aphids by genetic engineering. In this paper, the cloning of the lectin gene from P. ternata was presented, which will enable us to further test its effect in depth on aphids by transferring the gene into crop plants.

\section{MATERIALS AND METHODS}

\section{Plant materials and RNA isolation}

P. ternata plants were collected from Shanghai Chinese Medical University, China. The inflorescence from P. ternata, served as the starting material for RNA isolation, was powdered in liquid nitrogen with mortar and pestle and the total RNA was extracted using TRIzol Reagent (GIBCO BRL, USA) according to the manufacturer's instruction.

\section{3' RACE (Rapid Amplification of cDNA Ends) of P. ternata agglutinin (PTA) gene}

cDNA synthesis was performed with the 3' RACE System for Rapid Amplification of cDNA ends (RACE PCR Kit, GIBCO BRL, USA). Essentially, an aliquot of isolated RNA (120 ng) was reversely transcribed with a cDNA synthesis primer AP (adaptor primer, 5'GGCCACGCGTCGACTAGTAC $\left.(\mathrm{T})_{16^{-}} 3^{\prime}\right)$. As most of the monocot mannose-binding lectins have conservative mannose-binding sites with the conservative amino acid sequence being MQG/EDCNL, primer PXF2 (5'-ATGCAGGGCGACTGCAACCT-3') was designed according to the conserved amino acid sequence and synthesized (Shanghai Sangon Biotechnological Company, China). The 3' RACE was performed essentially according to the manufacturer's instructions. PCR was carried out in a total volume of $50 \mathrm{ml}$ containing $2 \mu \mathrm{l} \mathrm{cDNA}, 10 \mathrm{pmol}$ each of PXF2 and AP primers, $10 \mu M$ dNTPs, $1 \times$ cDNA reaction buffer and 5U Taq polymerase. PCR reaction for 3 ' and 5 ' RACE was the same and was performed under the following condition: cDNA was denatured at $94{ }^{\circ} \mathrm{C}$ for $5 \mathrm{~min}$ followed by 35 cycles of amplification $\left(94^{\circ} \mathrm{C}\right.$ for $30 \mathrm{sec}, 59^{\circ} \mathrm{C}$ for $50 \mathrm{sec}$, $72^{\circ} \mathrm{C}$ for $1 \mathrm{~min}$ ) and $5 \mathrm{~min}$ at $72^{\circ} \mathrm{C}$. The PCR product (PX3', $0.6 \mathrm{~kb}$ ) was purified and cloned into pGEM-T vector (Promega, Madison, WI, USA) followed by sequencing.

\section{5' RACE}

Based on the sequence of the 3 ' RACE product, specific primers PXR2 (5'-TAGTCACCCTGCTTGGAGCT-3') and PXR3 (5'TGTTGGACTGCCAGCCGTACTT-3') were designed to amplify the 5 ' end of PTA. The first round of PCR was performed with primer PXR2 and abridged anchor primer (AAP, 5' GGCCACGCGTCGACTAGTACGGGIIGGGIIGGGIIG-3'). The PCR product was diluted 50-fold for a second round of amplification with primer PXR3 and abridged universal amplification primer (AUAP, 5'-GGCCACGCGTCGACTAGTAC-3'). The PCR product (PX5', $0.8 \mathrm{~kb}$ ) was purified and cloned into pGEM-T vector followed by sequencing.

\section{Generation of PTA full-length cDNA sequence}

By comparing and aligning the sequences of PX3' and PX5', the full-length cDNA sequence of Pinellia ternata lectin gene was obtained through $\mathrm{RT}-\mathrm{PCR}$ reaction using primer $\mathrm{F} 1$ (5'AGTATCACGGCGAACAAGTA-3') and R1 (5' GGGGGGGAGCCATATTTATT-3'). The thermal cycling program was the same as that utilized for 3 ' and 5' RACE. It was then analyzed for the presentation of signal peptide and mannose-binding sites as described before[10].

\section{Southern blot analysis}

Total genomic DNA was isolated from $1 \mathrm{~g}$ fresh weight of $P$. ternata leaf tissue according to the procedure described before[]. Aliquots of DNA $(30 \mu \mathrm{g})$ were digested overnight at $37^{\circ} \mathrm{C}$ with $\mathrm{BamHI}$, PstI and EcoRI respectively, fractionated by $0.8 \%$ agarose gel electrophoresis, and transferred to a positively charged nylon membrane (Boehringer Mannheim). The probe for Southern hybridization was generated by PCR using the PXF1 (5'ATGGCCTCCAAGCTCCTCCT-3') and the PXR1 (5'ATTCACTCTTCTCCGTCACC-3') primers that amplified the coding sequence (about $0.8 \mathrm{~kb}$ ) of PTA gene. The probe was labeled with digoxigenin (DIG)-dUTP using the PCR DIG Probe Synthesis Kit (Boehringer Mannheim) and purified using QIAquick Gel Purification Kit (QIAGEN) according to the manufacturer's instructions. Hybridized bands were detected using the DIG Luminescent Detection Kit (Boehringer Mannheim) and signals were visualized by exposure to Fuji X-ray film at $37^{\circ} \mathrm{C}$ for $1 \mathrm{~h}$.

\section{Northern blot analysis}

Total RNA was isolated from roots, stems, leaves and inflorescences of $P$. ternata according to the manufacturer's instructions (TRIzol Reagents, Gibco, USA). Aliquots of total RNA (50 $\mu \mathrm{g})$ were denatured in glyoxal gel and DMSO and fractionated by $1.2 \%(\mathrm{w} / \mathrm{v})$ agarose gel. Following the electrophoresis RNA in the gel was transferred to a positively charged nylon membrane (Boehringer Mannheim). The probe and hybridization procedure for Northern blot analysis was the same as those for Southern blot analysis. Hybridized bands were detected using the DIG Luminescent Detection Kit (Boehringer Mannheim) and signals were visualized by exposure to Fuji X-ray film at $37^{\circ} \mathrm{C}$ for $1 \mathrm{~h}$. 


\section{Data analyses}

DNA sequences and associated molecular information were analyzed using programs from PCgene, Genepro, Vector NTI Suite 6.0 and Clustal W.

\section{Expression of PTA in E. coli}

The sequence encoding for the PTA mature protein was amplified with primer PX1 (5'-GCGCCATGGGTGGGCACCAACTACCTA$\left.3^{\prime}\right)$ containing NcoI restriction site and primer PX2 (5'GCGAAGCTTTTAATTCACTTCTCCGT-3') containing HindIII restriction site. The amplification product was digested with $\mathrm{NcoI}$ and HindIII and the digested fragment was ligated into bacterial expression vector $\mathrm{pET}-32 \mathrm{a}$ (Invitrogen) pre-digested with $\mathrm{NcoI}$ and HindIII. The resulting recombinant plasmid, pET-32a-PTA, contained the PTA mature protein sequence fused downstream of the gene encoding for the thioredoxin protein (Trx). Correct insertion of the fragment was confirmed by DNA sequencing. The recombinant plasmid was subsequently introduced into $E$. coli BL21(DE3) strain (Invitrogen).

When the $\mathrm{OD}_{600}$ of the $E$. coli BL21(DE3) harboring the recombinant plasmid (pET-32a-PTA) reached 0.6, IPTG ( $1 \mathrm{mM}$ ) was added into the culture and the culture continued growth at $37^{\circ} \mathrm{C}$ for $4 \mathrm{~h}$ to induce the expression of the fusion protein (Trx-PTA). The fusion protein was analyzed by SDS-PACE along with the $E$. coli BL21(DE3) and E. coli BL21(DE3) harboring pET-32a as controls.

\section{Artificial diet bioassays}

The artificial diet used was that described by Li for the rearing of aphids[12]. Purified PTA fusion protein was incorporated at $0.1 \%$ $(\mathrm{w} / \mathrm{v})$. Controls containing no protein and containing no diet were set up for each trial. The diet solution was incorporated into feeding vessels based on those described by Hilder et al [4]. Petri dishes (90 $\mathrm{mm}$ diameter) were lined with water-soaked filter paper. Ten neonate peach potato aphids (M. persicae Sulzer) were transferred from the host plant with a moistened camel hair brush and the petri dishes sealed with a stretched parafilm membrane. An aliquot of $500 \mu \mathrm{l}$ diet was added on the parafilm membrane and the diet was covered with a layer of stretched parafilm membrane to form a feeding sachet through which the aphids could imbibe the diet. Three replicates were set up for treatment and controls. The feeding chambers were maintained in greenhouse, illuminated with a 16/8 h light/ dark at a temperature of $252^{\circ} \mathrm{C}$. Diets were changed every other day to ensure a fresh nutrient supply. The number of surviving aphids was recorded every 2 days.

\section{RESULTS}

\section{Isolation and characterization of PTA gene}

Using the RACE PCR method the full-length cDNA of P. ternata lectin was cloned. It contained $1191 \mathrm{bp}$ with an 810 bp open reading frame encoding 269 amino acids with a calculated molecular mass of 29.4
$\mathrm{kD}$ (pI 6.58) (Fig 1). According to the rules of predicting lectin signal peptide[13], a 24-amino-acid signal peptide with the signal peptide-cleavage site being

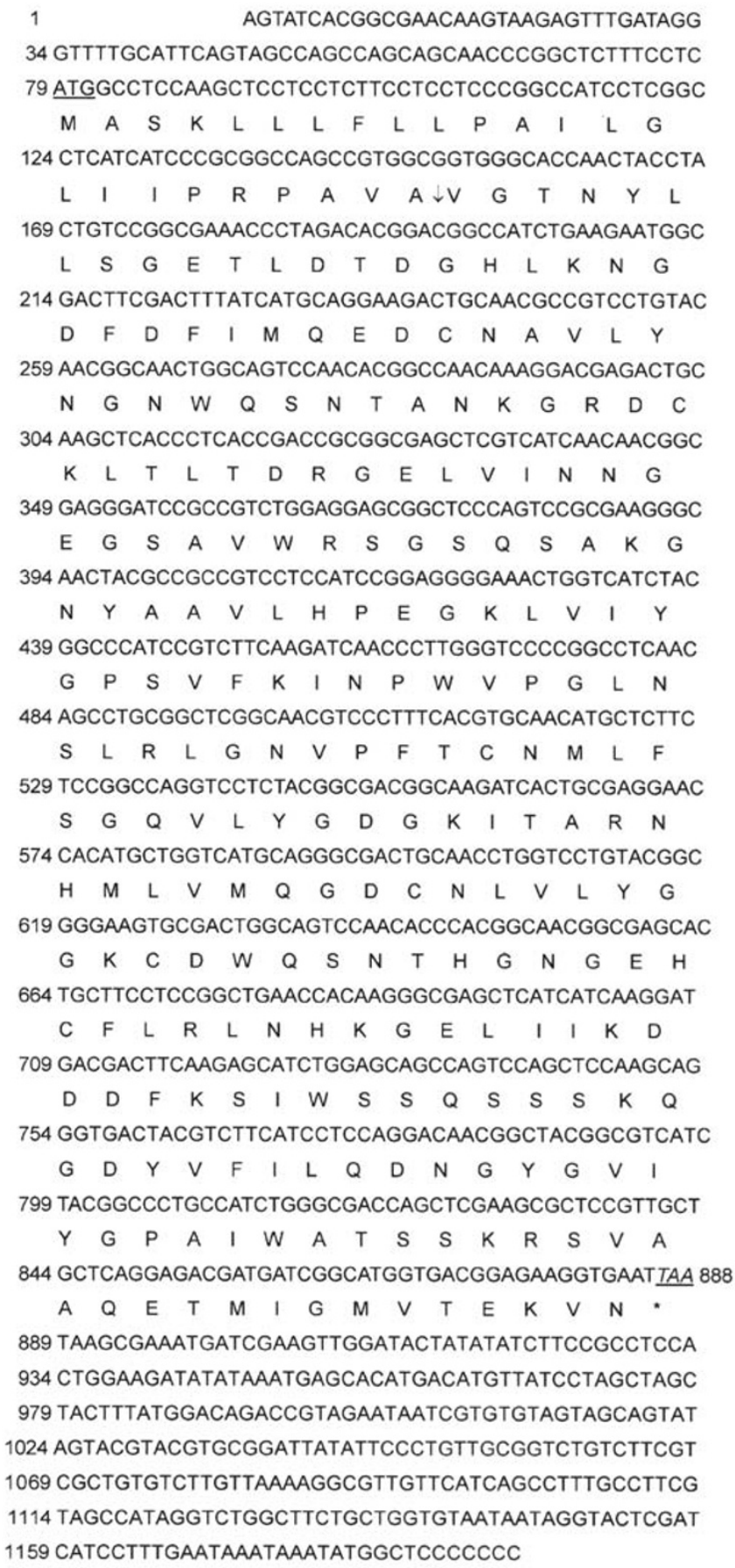

Fig 1. The full-length cDNA and deduced amino acid sequences of Pinellia ternata agglutinin (PTA). The start codon was underlined and the stop codon was underlined italically. The arrow indicated the cleavage site of signal peptide (between $\mathrm{A}$ and V). 
between $\mathrm{A} 24$ and $\mathrm{V}_{25}$ was identified from the PTA fulllength sequence. Thus, the deduced mature protein of PTA is composed of 245 amino acids with a calculated molecular mass of $26 \mathrm{kD}$ (pI 6.07).

\section{Sequence analysis of PTA}

A database search with BlastP2.2.3 (National Center for Biotechnology Information databases) showed that PTA was $72.8 \%$ identical to the $12 \mathrm{kDstorage}$

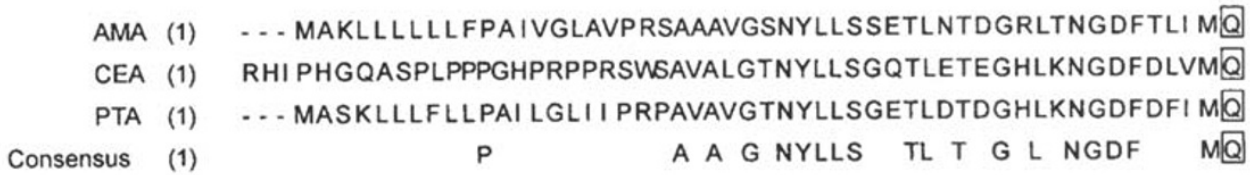

AMA (53) GDCNIVLI]NG- WQSNTANNGRDCKLTLTDFGELVIKSGTGSTVWSSGSKQSVKGN

CEA (56) D[D]CNLVL『NGNWQSNTANKGRDCKLTLTDHGELVINNGDGSTVWRSG- AQSVKGD

PTA (53) E[DCNAVYNGNWQSNTANKGRDCKLTLTDRGELVINNGEGSAVWRSG-SQSAKGN

consensus (56) DCN MUNNG WQSNTAN GRDCKLTLTD GELVI G GS WW SG QS KG

$\begin{array}{rll}\text { AMA } & \text { (107) } & \text { YAAVVHPEGRLVIYGPSVFKINPSVPGLNGLPLRNIPLTNNMLFSGQVLYGDGML } \\ \text { CEA } & \text { (110) } \\ \text { PAAVVHPEGRLVFSPSVFKIDPSVPGLNSLRFRNIPFTNNLLFSGQVLYGDGRL } \\ \text { PTA } & \text { (107) YAAVLHPEGKLVIYGPSVFKINPWVGLNSLRLGNVPFTCNMLFSGQVLYGDGKI } \\ \text { Consensus } & \text { (111) YAAV HPEG LV PSVFKI P VPGLN L N P T N LFGQVLYGDG }\end{array}$

AMA (162) SARNHKFIMQ⿹勹巳 DMVLYGGKYGWQSNTHGNGKYCFARLTHKGELVIKDDDFKSV

CEA (165) TAKNHQLVM Q

PTA (162) TARNHMLVM@G DC NLVLY]GGKCDWQSNTHGNGEHCFLRLNHKGELIIKDDDFKSI

Consensus (166) A NH MQGGCN VLY]GGK WQSNTHGNG CF RL HKGEL I DDDFK

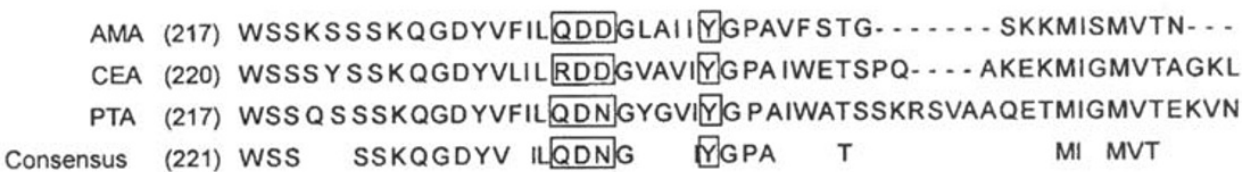

Fig 2. Comparison of amino acid sequences among PTA, AMA and CEA. Identical amino acid residues among the three lectins were indicated with single letters. Mannose-binding sites (QDNY) were boxed.

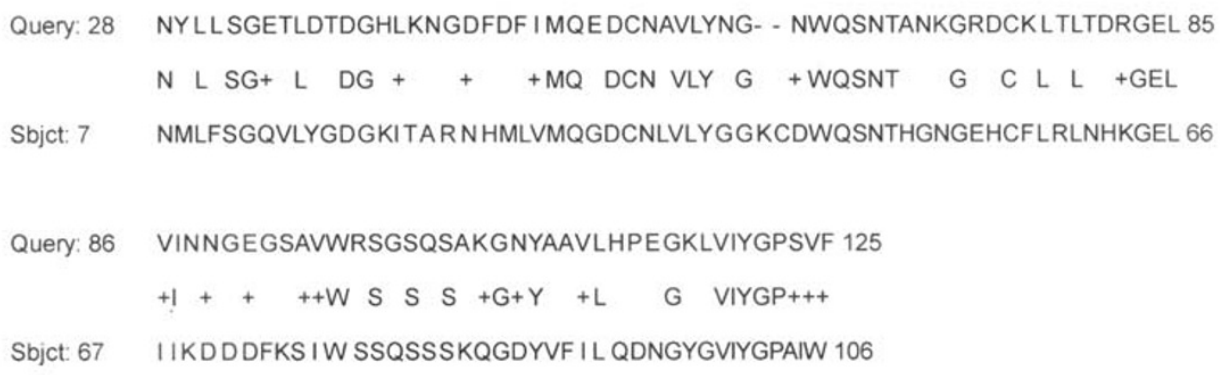

Fig 3. The alignment of amino acid sequences of the two domains within PTA. Query: Domain (A) Sbjct: Domain (B). Identical amino acid residues were indicated with "letter". Homologous amino acid residues were indicated with "+". 
protein (mannose-binding) in the tubers of Colocasia esculenta Schott (CEA)[14] and 70.7\% identical to the mannose-binding lectin from Arum maculatum (AMA) [15] (Fig 2).

The computer analysis detected two putative conserved domains of similar size in PTA protein deduced from the cloned pta gene that were agglutinins or lectins (mannose-binding). Domain A was between $\mathrm{T}_{27}$ and $\mathrm{W}_{130}$ amino acid (calculated molecular mass of $11.4 \mathrm{kD}$ ) and Domain B was between $\mathrm{C}_{147}$ and $\mathrm{S}_{250}$ (calculated molecular mass of $11.6 \mathrm{kD}$ ). They were $42 \%$ identity (Fig 3).

Analysis of the secondary and three-dimensional structures of PTA
The secondary and three-dimensional structures of PTA were analyzed with Vector NTI Suite 6.0 (Fig 4). PTA consisted of twenty-one $\beta$-sheets connected with turns and coils (Fig 4a). The signal peptide and the C-terminal formed $a$-helix. It was noteworthy that $\beta$-sheets occurred predominantly in the structure of PTA. The overall folding of PTA, which was typically built from $\beta$-sheets connected by turns and loops, created very tight structural scaffold (Fig $4 \mathrm{~b}$ ). Mannose-binding sites emerged from the convergence of flexible loops, which was proved to be important to enhance the ability of lectins to bind mannose[16]. PTA had three conserved mannose-binding sites (QDNY) which were symmetrically arranged on PTA molecular (Fig 4).

A

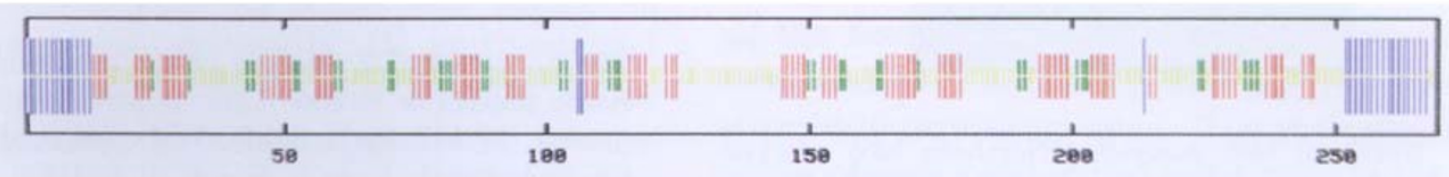

B

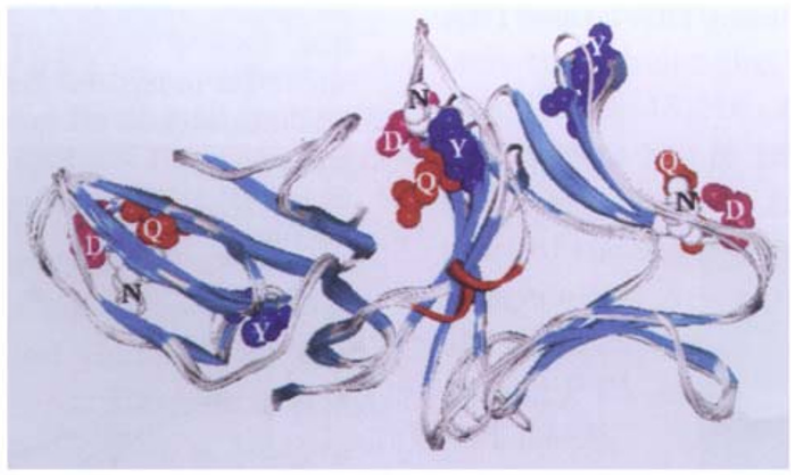

Fig 4. The secondary and three-dimensional structures of PTA. (A) The secondary structure. Helix, sheet, turn and coil were indicated respectively with blue, red, green and yellow vertical lines. (B) The threedimensional structure. b-sheets and a-helices were indicated in green and red patches. Turns and loops were indicated in silver patches. The amino acid residues constituting mannose-binding sites were indicated as balls.

By above comparison of the structure of PTA and other mannose-binding lectins, PTA was found to have many characters commonly possessed by mannosebinding lectin family. It was a heterotetrameric member of the family of Araceae lectins. The X-ray crystal structure analysis will further elucidate the detailed structure of PTA.

\section{Northern blot analysis}

To investigate the pta expression patterns in various tissues of P. ternata, total RNA was isolated from different tissues and allowed to hybridize with the DIG-labeled PTA coding sequence. Northern blot analysis revealed that strong hybridization signals were detected in all the tested tissues including inflorescence, root, stem and leaf (Fig 5). As the pta mRNA was detected in all the tested plant tissues, the $p t a$ was considered to be a constitutively expressing gene.

\section{Southern blot analysis}

In order to test if the pta belongs to a multigene 
family, Southern blot analysis was performed by digesting the genomic DNA isolated from $P$. ternata leaves with various restriction enzymes (Bam HI, PstI and EcoRI) respectively and allowed to hybridize with the DIG-labeled PTA coding sequence(Fig 6). The result revealed that there were a few hybridization bands, indicating the pta belongs to a low copy gene family.

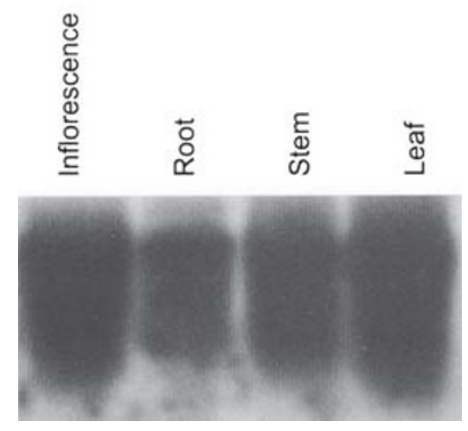

Fig 5. Northern blot analysis. Northern blot analysis of PTA mRNA expression in Pinellia ternata inflorescence, root, stem and leaf was performed using DIG-labeled PTA coding sequence as a probe.

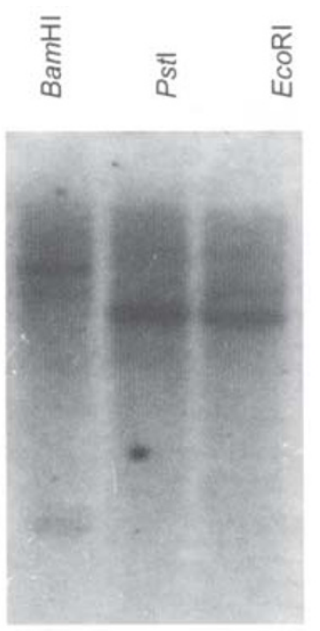

Fig 6. Southern blot analysis. Genomic DNA was isolated from leaves of Pinellia ternata and digested with BamHI, PstI, EcoRI respectively followed by hybridization with the DIG-labeled PTA coding sequence.

\section{Expression of PTA fusion protein in E. coli}

The pta cDNA sequence encoding for mature PTA protein was cloned into $\mathrm{pET}-32 \mathrm{a}$ plasmid and the resulting plasmid, pET-32a-PTA containing Trx-PTA fusion protein was investigated for the expression in E. coli BL21(DE3). SDS-PAGE gel analysis showed that the Trx-PTA fusion protein was successfully ex- pressed in E. coli BL21 when induced by IPTG (Fig 7). The molecular weight of the expressed PTA, when subtracting the Trx from Trx-PTA, was the similar size with that of the deduced mature PTA, indicating the pta could be normally translated in $E$. coli as predicted.

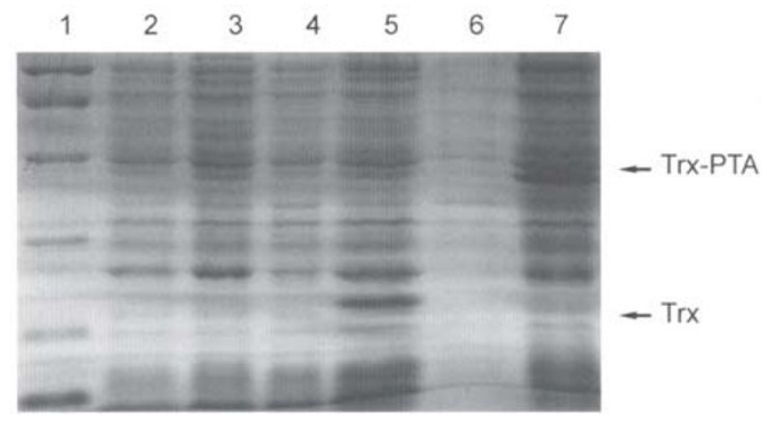

Fig 7. SDS-PAGE analysis of the expression of Trx-PTA fusion protein in $E$. coli. Lane 1: protein molecular weight marker (97 $\mathrm{kD}, 66 \mathrm{kD}, 43 \mathrm{kD}, 31 \mathrm{kD}, 20 \mathrm{kD}$ and $14 \mathrm{kD}$ from top to bottom). Lane 2: $E$. coli BL21(DE3) without IPTG induction. Lane 3: $E$. coli BL21(DE3) with IPTG induction. Lane 4: $E$. coli BL21 (DE3) harboring pET-32a without IPTG induction. Lane 5: $E$. coli BL21(DE3) harboring pET-32a with IPTG induction. Lane 6: $E$. coli BL21(DE3) harboring pET-32a-PTA without IPTG induction. Lane 7: E. coli BL21(DE3) harboring pET-32a-PTA with IPTG induction.

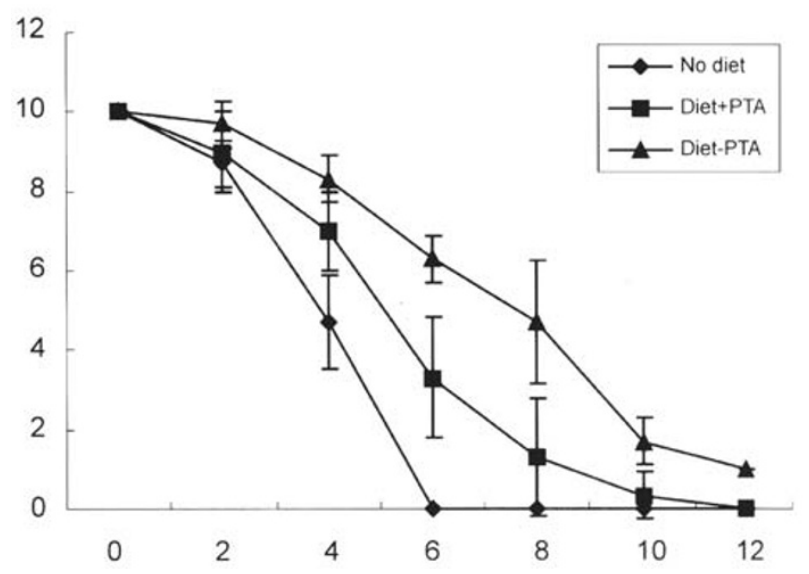

Fig 8. Artificial diet bioassay of the PTA fusion protein against peach potato aphids (Myzus persicae Sulzer). No diet: aphids were fed without diet. Diet-PTA: aphids were fed with diet containing no PTA fusion protein. Diet+PTA: aphids were fed with diet containing $0.1 \%(\mathrm{w} / \mathrm{v})$ PTA fusion protein.

\section{Aphid artificial diet assay}

The insecticidal effect of PTA fusion protein against peach potato aphids has been tested at $0.1 \%(\mathrm{w} / \mathrm{v})$ in a 
wholly defined artificial diet. Results showed that PTA fusion protein had significant levels of resistance against aphids (Fig 8). All the aphids fed without diet died on day 6 . The mean number of aphids fed with diet containing $0.1 \%$ PTA fusion protein was significantly less than that fed only with diet constantly throughout the assay period with the differences significant at $\mathrm{P}<0.05$ after day 6 , and all the aphids fed with diet containing $0.1 \%$ PTA fusion protein died on day 12 .

\section{DISCUSSION}

In the present study, we report the successful cloning of the full-length cDNA of P. ternata lectin (pta) using the RACE PCR method. The full-length cDNA of pta was $1191 \mathrm{bp}$, a size very similar to those of other Araceae species[14, 15], and contained a 810 bp open reading frame encoding 269 amino acids. Like mannose-binding lectins of other Araceae species such as C. esculenta and A. maculatum[14, 15], PTA was predicted to have a signal peptide and the deduced mature protein of PTA was composed of 245 amino acids. A database search with BlastP2.2.3 showed that PTA had high homology with mannose-binding lectins from C. esculenta (CEA)[14] and A. maculatum (AMA)[15], indicating PTA was a member of monocot mannose-binding lectin superfamily. Previous reports indicated that all the characterized Araceae lectins such as CEA and AMA were heterotetramers composed of four polypeptide chains. Two chains were identical but different from other two chains. Each chain had similar size of $11-14 \mathrm{kD}[14,15]$. Studies on the purification of PTA from tubers of P. ternata revealed that PTA was a tetramer of $40-50 \mathrm{kD}$ composed of four polypeptide chains, each with similar molecular mass of 11-14 $\mathrm{kD}$ but with different $\mathrm{pI}[8,9]$. In the present study, the computer analysis also detected two putative conserved domains of similar size in PTA protein deduced from the cloned pta gene that were agglutinins or lectins (mannose-binding). It was presumed that PTA, like CEA and AMA, was first synthesized as a large precursor that was post translationally processed into two polypeptides of similar size. The two polypeptides were respectively composed of, namely, domain A and domain B. Therefore computer analysis confirmed the result from the purification of PTA from the tubers[8, 9] that, like CEA and AMA, PTA was heterotetramer composed of four non-covalently linked polypeptide chains of similar size.

Sequence analysis revealed that PTA had three conserved mannose-binding sites (QDNY). The amino acid sequences of the sites were the same or similar as those of GNA[17, 18], CEA[14] and AMA[15] and symmetrically arranged on PTA molecular. The structure of PTA was very similar to the three-dimensional structures of other plant mannose-binding lectins[10, $14,15,19]$, further implying that PTA was a monocot mannose-binding lectin.

In the present study, Northern blot was performed to investigate the expression pattern of the pta in various tissues of $\mathrm{P}$. ternata. The result showed that the pta mRNA could be detected in all the tested tissues including inflorescence, root, stem and leaf, indicating that the pta was a constitutively expressing gene. The presence of multicopies of mannose-binding lectin gene in the genome has been reported in some plant species, particularly those belonging to Amaryllidaceae and Araceae families[10, 15, 16, 20]. Southern blot analysis in the current study indicated that the pta belonged to a low copy gene family, which was different from most of the mannose-binding lectin genes from other Araceae and Amaryllideae species[10, 14, 15, 17, 20] although extensive sequence homologies were found among PTA and other Araceae species such as CEA and AMA.

Earlier studies showed that many mannose-binding lectins from monocotyledonous families Amaryllidaceae and Araceae had more or less insecticidal activities in feeding experiments with both artificial and transgenic plants[2, 4, 5, 8, 9]. It was also found that the insecticidal activities of lectins were directly proportional to the number of subunits possessed by lectins. Tetrameric lectins had generally higher insecticidal activities than dimeric lectins[16]. Recent insect bioassay studies showed that lectins (tetrameric) from P. pedatisecta and P. ternata had significant insecticidal activities towards cotton aphids (A. gossypii Glover) and peach potato aphids (M. persicae Sulzer)[8, 9]. Our current aphid artificial bioassay result is consistent with the previous result on feeding aphids with purified PTA isolated from the plant tubers[8], indicating the potential utilization of the pta gene in crop protection against aphids by ge- 
netic engineering. In addition to anti-pest properties, recent studies showed that some mannose-binding lectins from monocotyledonous species such as gastrodianin from Ochidaceae also had antifungal properties[21]. The cloning of $\mathrm{P}$. ternata lectin gene will enable us to further test its role in depth in controlling pests and fungal diseases by transferring the gene into crop plants.

\section{ACKNOWLEDGEMENTS}

This work was funded by China National Transgenic Plant Research and Commercialization Project, China National "863" High-Tech Program, China Ministry of Education, Shanghai Science and Technology Committee and China-UK Science and Technology Collaboration Fund.

\section{REFERENCES}

1. Mochida O, Wahyu A, Surjani TK. Some considerations on screening resistant cultivars/lines of rice plant to the brown planthopper, Nilparvata lugens (Stal) (Hom, Delphacidae). Los Banos, Philippines: IRRI, 1979; 1:1-9.

2. Powell KS, Gatehouse AMR, Hilder VA, Gatehouse JA. Antimetabolic effects of plant lectins and plant and fungal enzymes on the nymphal stages of two important rice pest, Nilaparvata lugens and Nephotettix cinciteps. Entomol Exp Appl 1993; 66:19-126.

3. Powell KS, Gatehouse AMR, Hilder VA, Gatehouse JA. Antifeedant effects of plant lectins and enzymes on the adult stage of the rice brown planthopper, Nilaparvata lugens. Entomol Exp Appl 1995; 75:51-9.

4. Hilder V., Powell KS, Gatehouse AMR, Gatehouse JA. Expression of snowdrop lectin in transgenic tobacco plants results in added protection against aphids. Transgenic Res 1995; 4:18-25.

5. Rao KV, Rathore KS, Hodges TK, et al. Expression of snowdrop lectin (GNA) in transgenic rice plants confers resistance to rice brown planthopper. Plant J 1998; 15:469-77.

6. Tang K, Zhao Z, Sun X, Wan B, Qi H, Lu X. Production of transgenic rice homozygous lines with enhanced resistance to rice brown planthopper. Acta Biotechnol 2001; 21:11728.

7. Wu A, Sun X, Pang Y, Tang K. Homozygous transgenic rice lines expressing GNA with enhanced resistance to the rice sap-sucking pest Laodelphax striatellus. Plant Breed 2002; 121:93-5.
8. Huang DF, Pan YH, Zhang SX, Cao JP, Yang XM, Zhang J, Yin WZ. The discovery of insecticidal protein against aphids from Pinellia pedatisecta and P. ternata. Sci Agri Sin 1997; 30:94.

9. Pan YH, Zhang SX, Cao JP, Huang DF. The isolation, purification of Pinellia pedatisecta lectin and its activity on aphidresistance. Progress Nat Sci 1998; 8:502-5.

10. Van Damme EJM, Goldstein IJ, Vercammen G, Peumans WJ. Lectins of members of the Amaryllidaceae are encoded by multigene families which show extensive homologies. Physiol Plant 1992; 86:245-52.

11. Dellaporta SL, Wood J, Hicks JB. A plant DNA minipreparation:version II. Plant Mol Biol Rep 1983; 1: 19-21.

12. Li L, Gao L, Gao Y. Li. Studies on rearing aphids with artificial nutrition solution. J Shanxi Agric Univ 1997; 17:2258.

13. Van Heijine G. A new method for predicting signal sequence cleavage sites. Nucl Acids Res 1986; 14:4683-90.

14. Hirai M, Nakamura K, Imai T, Sato T. cDNAs encoding for storage proteins in the tubers of taro (Colocasia esculenta Schott). Jpn J Genet 1993; 68:229-36.

15. Van Damme EJM, Goossens K, Smeets K, Van Leuven F, Verhaet P, Peumans WJ. The major tuber storage protein of Araceae species is a lectin: Characterization and molecular cloning of the lectin from Arum maculatum. Plant Physiol 1995; 107:1147-58.

16. Barre A, Bourne Y, Van Damme EJM, Peumans WJ, Rouge P. Mannose-binding plant lectin: different structural scaffolds for a common sugar-recognition process. Biochimie 2001; 83:645-51.

17. Hester G, Kaku H, Goldstein IJ, Wright CS. Structure of mannose-specific snowdrop (Galanthus nivalis) lectin is representative of a new plant lectin family. Nat Struct Biol 1995; 2:472-9.

18. Hester G, Wright CS. The mannose-specific bulb lectin from Galanthus nivalis (snowdrop) binds mono- and dimannosides at distinct sites: Structure analysis of refined complexes at 2.3 A and 3.0 A resolution. J Mol Biol 1996; 262:516-31.

19. Barre A, Van Damme EJM, Peumans WJ, Rouge P. Structure-function relationship of monocot mannose-binding lectins. Plant Physiol 1996; 112:1531-40.

20. Van Damme EJM, Kaku H, Perini F, Peumans WJ. Biosynthesis, primary structure and molecular cloning of snowdrop (Galanthus nivalis L.) lectin. Eur J Biochem 1991; 202:23-30.

21. Wang XC, Bauw G, Van Damme EJM, Peumans WJ, Chen ZL, Van Montagu M, Angenon G, Dillen W. Gastrodianinlike mannose-binding proteins: a novel class of plant proteins with antifungal properties. Plant J 2001; 25:651-61. 